\title{
TEC no Âmbito do Mercosul: Teoria e Prática ${ }^{1}$
}

\section{Mercosur's CET: Theory and Practice}

André Filipe Zago de Azevedo ${ }^{2}$ Angélica Massuquetti ${ }^{3}$

Resumo: O Mercosul, apesar de avanços significativos obtidos em seu processo de integração, ainda apresenta uma série de furos e brechas, em especial em relação a sua tarifa externa comum (TEC). Este artigo analisa as políticas dos países do Mercosul em relação às tarifas extrabloco nos anos 1990, comparando-as com as abordagens teóricas que explicam a sua determinação. As duas principais abordagens para explicar a determinação da TEC em uma união aduaneira, dos termos de troca e da formação endógena de tarifas, parecem dar suporte teórico para o aumento de protecionismo do Mercosul em relação a países não membros do bloco observado após a implementação da TEC.

Palavras-chave: Integração regional. Política comercial. Mercosul.

Abstract: Mercosur, despite has achieved important advances in its integration process, still presents some holes and loopholes, especially those related to the common external tariff (CET). This paper analyses Mercosur countries policies in relation to extrabloc tariffs in 1990s, comparing them with theoretical approaches that explain their determination. The two main approaches that explain the CET determination in a customs union, terms of trade and endogenous tariff formation, seem to give theoretical support to the increase in Mercosur protectionism in relation to non-members of the bloc occurred after the CET's implementation.

Keywords: Regional integration. Trade policy. Mercosur.

JEL Classification: F15; F13.

\section{Introdução}

O ressurgimento de acordos preferenciais de comércio (ACP) tem sido uma das características mais marcantes dos últimos anos. Este

$1 \quad$ Os autores agradecem a Aki Kuwahara da UNCTAD pelo fornecimento de dados.

2 Coordenador do Mestrado em Economia da Universidade do Vale do Rio dos Sinos (UNISINOS). Pesquisador do CNPq. E-mail: aazevedo@unisinos.br

3 Coordenadora do Curso de Graduação em Ciências Econômicas da Universidade do Vale do Rio dos Sinos (UNISINOS). E-mail: angelicam@unisinos.br 
fenômeno é conhecido como a $2^{\mathrm{a}}$ onda de regionalismo, em contraste com a $1^{a}$ onda, ocorrida nas décadas de 1950 e 1960, e já atinge quase a totalidade dos países integrantes da Organização Mundial de Comércio (OMC) ${ }^{4}$ A formação do Mercado Comum do Sul (Mercosul) coincide com o boom da nova onda de regionalismo dos anos de 1990. Criado em março de 1991, pelo Tratado de Assunção, seu principal objetivo era a consolidação de um mercado comum entre Argentina, Brasil, Paraguai e Uruguai. Nesse sentido, o comércio intrabloco deveria estar imune a tarifas de importação e as tarifas aplicadas em importações de países de fora do bloco convergiriam para uma tarifa externa comum (TEC).

De um lado, o Mercosul obteve progressos importantes como o estabelecimento de uma TEC para a maioria dos produtos. Entretanto, apesar da intenção de adotar medidas típicas da $2^{\mathrm{a}}$ onda de regionalismo, o bloco tem permitido uma variada gama de exceções às regras inicialmente acordadas, conforme constata a literatura que trata do processo de formação do Mercosul (por exemplo, LAIRD, 1997; PREUSSE, 2001; AZEVEDO, 2004; KUME; PIANI, 2005). Além disso, a longa história de insucessos na formação de blocos regionais na América do Sul, que remontam aos anos de 1960, e alguns acontecimentos recentes têm criado dúvidas quanto à capacidade dos países membros do bloco de alcançar seus objetivos ambiciosos.

Este artigo tem como objetivo identificar os principais furos e bre$\operatorname{chas}^{5}$ do bloco especificamente no que diz respeito à TEC, além de buscar explicar como ocorreu a sua determinação inicial. A determinação da TEC em uma união aduaneira tem sido explicada pela literatura através de duas abordagens distintas: a dos termos de troca e a da formação endógena de tarifas (por exemplo, CADOT et al.; 1996; WINTERS, 1996; OLARREAGA et al., 1999). A primeira relaciona o estabelecimento da TEC à tentativa de uma melhoria dos termos de troca dos membros do bloco em relação ao resto do mundo, enquanto a segunda busca explicar a formatação da TEC como uma forma de redistribuir renda para determinados grupos organizados da sociedade. Essa relação entre a evolução da TEC e as abordagens teóricas que a justificam é a maior contribuição do artigo.

O artigo está dividido em três seções, além desta introdução. A primeira faz uma sucinta descrição da liberalização unilateral empreendida pelos membros do Mercosul antes da formação da união aduaneira,

$4 \quad$ Ver Lawrence (1997) e Ethier (1998) para uma resenha das principais diferenças entre as duas ondas de regionalismo.

5 Estas expressões assumem o significado dado por Hoekman e Leidy (1993), onde um furo (hole) constitui uma exclusão ou exceção e uma brecha (loophole) significa uma válvula de escape ou salvaguarda em relação às regras do acordo. 
em 1995, quando os países ainda detinham o controle de suas tarifas extrabloco. A segunda examina a formatação apresentada pela TEC, as principais exceções inicialmente permitidas e as novas perfurações incorporadas ao longo dos anos, bem como as principais abordagens teóricas para a determinação da TEC quando da formação de uma união aduaneira. Finalmente, a última seção apresenta as conclusões.

\section{Liberalização Unilateral Pré-Mercosul}

Após um longo período no qual medidas protecionistas ocupavam o centro da sua estratégia de desenvolvimento, a América Latina iniciou um processo de mudança de sua política comercial, a partir da metade dos anos 1980. A generalizada liberalização comercial promovida pelos países da região é extensamente documentada pela literatura (por exemplo, EDWARDS, 1995; LOAYZA; PALACIOS, 1997; LOSER; GUERGUIL, 1999). Uma série de motivos contribuiu para a profunda transformação pela qual passaram os países latino-americanos. Desde a crise da dívida externa de 1982, passando pelo fraco desempenho econômico da estratégia de substituição de importações nos anos 1980, em comparação com o rápido crescimento observado nos países do leste asiático, a crescente conversão dos economistas na defesa de uma política comercial mais liberal e o condicionamento da concessão de ajuda financeira à liberalização comercial e financeira pelas organizações multilaterais.

Os membros originais do Mercosul (Argentina, Brasil, Paraguai e Uruguai) não ficaram imunes a esta pressão. Sob velocidades variadas e iniciando em períodos diferenciados, conforme destacado por Estevadeordal et al. (2000), os futuros membros do bloco reformaram suas políticas comerciais unilateralmente. Os principais elementos da reforma comercial, sumarizados por Edwards (1994), foram a redução da média e do grau de dispersão das tarifas de importação, a redução da cobertura das barreiras não-tarifárias e a eliminação de taxas de exportação.

Conforme salientado, a redução da tarifa média de importação teve um papel importante no processo de liberalização comercial nos países da América Latina. A Figura 1 mostra que todos os futuros integrantes do Mercosul reduziram significativamente suas tarifas médias entre 1985 e 1994. O Brasil foi o país que promoveu o maior corte de tarifas de importação, passando de uma média de 55\%, em 1985, para $12,8 \%$, em 1994. Até mesmo o Paraguai, que apresentava a menor tarifa média entre estes países na década de 1980, promoveu uma drástica redução de suas tarifas e, em 1994, a tarifa média era inferior a metade do nível observado em 1985. A dispersão das tarifas também declinou 
substancialmente em todos os países, especialmente no Brasil, onde a queda chegou a 75\% neste período (ESTEVADEORDAL et al., 2000).

O Uruguai foi o primeiro país do bloco a iniciar seu processo de liberalização comercial, ainda na metade da década de 1980. Entretanto, houve uma intensificação deste processo somente a partir de 1990, com a estrutura tarifária sendo simplificada para apenas quatro faixas de alíquotas (15\%, 20\%, 30\% e 40\%). A política tarifária foi novamente modificada em setembro de 1991 e abril de 1992, resultando em um sistema com apenas três faixas de alíquotas (10\%, 17\% e 24\%). Posteriormente, as alíquotas foram reduzidas para $6 \%, 15 \%$ e $20 \%$ e mantidas nestes níveis até 1994 (OMC, 1998a). Além disso, após 1991, todas as proibições às importações foram eliminadas e as inúmeras barreiras não-tarifárias aplicadas sobre as importações, tais como taxas consulares e preços de referência de importação, foram reduzidas (ESTEVADEORDAL et al., 2000).

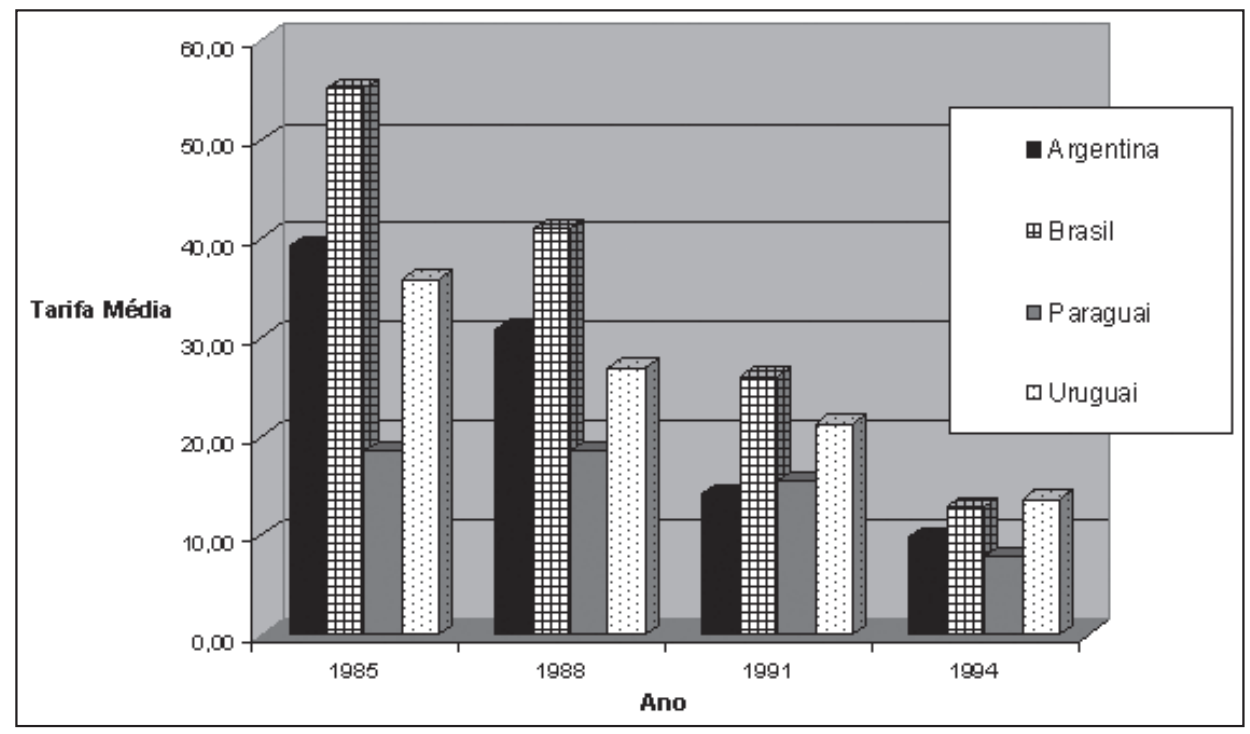

Figura 1 - Tarifa Média dos Países do Mercosul (1985-94)

Fonte: Comtrade - UNCTAD e Estevadeordal et al. (2000).

Em contraste com os demais membros do Mercosul, o Paraguai nunca adotou como um dos pilares de sua estratégia de desenvolvimento a política de substituição de importações, pois seu setor industrial é dominado por pequenas empresas orientadas para o mercado interno processando produtos oriundos do setor primário (OMC, 1997). A reforma comercial iniciou-se em 1989 e buscava racionalizar seu regime comercial ao simplificar a estrutura tarifária, reduzir alíquotas e remover proibições às importações de diversos produtos. No entanto, somente em julho de 1992 houve a introdução de uma estrutura tarifária baseada em apenas três níveis de alíquotas (zero para insumos, 5\% para bens de 
capital e 10\% para bens de consumo), com a única exceção sendo os automóveis, com alíquotas situando-se entre $15 \%$ e $20 \%{ }^{6}{ }^{6}$

O processo de redução das tarifas de importação e barreiras nãotarifárias na Argentina também foi implementado em 1988, intensificandose em 1991. A liberalização começou no final da década de 1980 com a redução unilateral das tarifas de importação e com a eliminação gradual de diferentes mecanismos que direta ou indiretamente obstruíam as operações de importação e exportação. ${ }^{7}$ A política tarifária passou por profundas mudanças entre o final dos anos 1980 e o início da década de 1990. Inicialmente, em outubro de 1988, o intervalo de variação das alíquotas que era de 15\%-53\% passou para um intervalo de zero-40\%, embora algumas exceções ainda persistissem (por exemplo: alíquotas de importação de automóveis eram de 115\%). Ao final de 1989, a alíquota máxima foi reduzida para 30\%, embora algumas tarifas específicas ainda estivessem em vigor. Em maio de 1991, foi estabelecida uma estrutura tarifária baseada em três níveis de alíquotas (zero, $11 \%$ e 22\%), simplificando o complexo e disperso sistema anterior vigente até o final dos anos 1980. Em novembro de 1991, o sistema foi, mais uma vez, modificado, ampliando para cinco os níveis de alíquotas (zero, 5\%, 13\%, 22\% e 35\%). Finalmente, durante o ano de 1992, o número de alíquotas diferenciadas elevou-se para nove, variando de zero a $20 \%$, permanecendo nestes patamares até o final de 1994 (ESTEVADEORDAL et al., 2000).

Em relação ao Brasil, o primeiro conjunto de medidas para reduzir o nível de protecionismo foi tomado em maio de 1988, com uma queda da média e do desvio padrão das alíquotas de importação e a eliminação de uma pequena parcela dos regimes especiais de importação. Em setembro de 1989, houve uma nova rodada de redução tarifária, levando a tarifa média de importação a declinar de 51\%, em 1987, para 35,5\% em 1989. ${ }^{8}$ Em 1990, a liberalização comercial foi aprofundada com a criação de um programa de redução das tarifas de importação e a eliminação da maioria das barreiras não-tarifárias e dos regimes especiais de importação. ${ }^{9}$ Em relação às tarifas, o programa estabeleceu uma redução gradual da média, da moda e do desvio padrão entre janeiro

6 É importante salientar que a redução promovida em julho de 1992 buscou alinhar as tarifas do Paraguai para a negociação da tarifa externa comum do Mercosul, buscando minimizar o desvio de comércio em favor de Argentina e Brasil, especialmente nos produtos industrializados.

7 De acordo com Berlinski (1994), em 1989, dois terços das linhas tarifárias, que eram alvo de alguma restrição quantitativa foram liberalizados.

8 Além da redução das tarifas de importação durante o período 1988-89, barreiras não-tarifárias foram removidas, como a redução do número de produtos incluídos na lista de importações proibidas, que declinaram de aproximadamente 2.400 para 1.200 .

9 Exemplos destas medidas foram a eliminação da lista de produtos com importação proibida e o fim da obrigação de financiamentos externos para as importações acima de US $\$ 200$ mil. 
de 1991 e dezembro de 1994. Para atingir tal objetivo uma estrutura de sete níveis de alíquotas foi criada, variando entre zero e $40 \%$, de acordo com o grau de competitividade e da existência de similar nacional (KUME, 1998; AZEVEDO; PORTUGAL, 1998). ${ }^{10}$

Assim, entre a metade da década de 1980 e 1994, os países que originalmente formaram o Mercosul seguiram a mesma tendência dos demais países da América Latina, reduzindo, de forma unilateral, a estrutura protecionista até então em vigor. Ao longo deste período, a média e a dispersão das tarifas de importação declinaram significativamente. Este processo remodelou os regimes de comércio da região e, desta forma, quando a TEC do Mercosul foi introduzida, os países já apresentavam tarifas de importação muito mais baixas do que aquelas praticadas na década anterior. Em alguns casos, como a próxima seção irá demonstrar, a implementação da TEC, em 1995, e alguns acontecimentos a posteriori reverteram o grau de liberalização obtido antes de 1994.

\section{Tarifa Externa Comum}

A TEC do Mercosul, conforme estabelecia o Tratado de Assunção, foi lançada em $1^{\circ}$ de janeiro de 1995 , sendo estruturada em onze níveis de tarifas, com um intervalo de 2 pontos percentuais, variando de zero a $20 \%$, apresentando uma média não-ponderada de 11,2\%. Ela se baseia na Nomenclatura Comum do Mercosul (NCM), que apresenta os primeiros 6 dígitos idênticos ao do Sistema Harmonizado (SH), enquanto o sétimo e o oitavo dígitos foram definidos de acordo com critérios estabelecidos pelos membros do bloco. Os setores mais protegidos, como mostra a Tabela 1, são armas e munições (20,0\%), calçados (19,1\%), matérias têxteis (17,3\%), produtos alimentares (14,9\%) e material de transporte $(14,8 \%)$; ao passo que os menos protegidos são produtos

10 Em linhas gerais, a determinação da nova política tarifária estabeleceu a seguinte orientação:

(I) tarifa zero: produtos com vantagens comparativas naturais (principalmente produtos primários e semi-manufaturados de exportação tradicional), com proteção natural (devido aos elevados custos de transporte), sem produção doméstica e commodities de baixo valor agregado;

(II) tarifa de 5\%: produtos que já apresentavam alíquota de importação de 5\%;

(III) tarifas entre 10 e 15\%: bens que utilizavam como principais insumos produtos com alíquota zero;

(IV) tarifa de 20\%: manufaturados em geral;

(V) tarifa de 30\%: química fina, trigo descascado, carne, biscoitos, massas alimentícias, aparelhos de TV, videocassetes e equipamentos de som;

(VI) tarifa de 35\%: automóveis, caminhões e motocicletas;

(VII) tarifa de 40\%: produtos de informática. 
minerais $(2,4 \%)$, trabalhos de arte $(4,0 \%)$, madeira $(6,9 \%)$ e produtos químicos $(7,6 \%)$.

Tabela 1 - TEC do Mercosul SH a 8 dígitos (1995)

\begin{tabular}{|c|c|c|c|c|c|c|c|}
\hline $\begin{array}{l}\text { Capítulos } \\
\text { do SH }\end{array}$ & Descrição & $\begin{array}{c}\text { No de } \\
\text { Linhas } \\
\text { Tarifárias }\end{array}$ & $\begin{array}{c}\text { Média } \\
\text { Simples }\end{array}$ & $\begin{array}{l}\text { Desvio } \\
\text { Padrão }\end{array}$ & Moda & Máximo & Mínimo \\
\hline 01-05 & $\begin{array}{l}\text { Animais vivos } \\
\text { e seus produtos }\end{array}$ & 252 & 9.1 & 4.0 & 10.0 & 16.0 & 0.0 \\
\hline $06-14$ & $\begin{array}{l}\text { Produtos } \\
\text { do reino vegetal }\end{array}$ & 355 & 7.7 & 3.9 & 10.0 & 14.0 & 0.0 \\
\hline $15-15$ & $\begin{array}{l}\text { Gorduras e óleos } \\
\text { veg. e anim. }\end{array}$ & 77 & 8.5 & 3.6 & 10.0 & 12.0 & 2.0 \\
\hline $16-24$ & $\begin{array}{l}\text { Prod. das indústrias } \\
\text { alimentares }\end{array}$ & 255 & 14.9 & 3.9 & 16.0 & 20.0 & 6.0 \\
\hline $25-27$ & Produtos minerais & 211 & 2.4 & 1.8 & 4.0 & 6.0 & 0.0 \\
\hline $28-38$ & $\begin{array}{c}\text { Produtos das indústrias } \\
\text { químicas }\end{array}$ & 2.587 & 7.6 & 5.5 & 2.0 & 18.0 & 0.0 \\
\hline $39-40$ & Plásticos e borracha & 356 & 12.2 & 5.4 & 14.0 & 18.0 & 0.0 \\
\hline $41-43$ & Peles e couros & 108 & 10.9 & 6.5 & 10.0 & 20.0 & 2.0 \\
\hline $44-46$ & Madeira e seus artigos & 120 & 6.9 & 3.9 & 10.0 & 14.0 & 2.0 \\
\hline $47-49$ & $\begin{array}{l}\text { Pasta de madeira, } \\
\text { papel, etc. }\end{array}$ & 159 & 12.1 & 4.5 & 12.0 & 16.0 & 0.0 \\
\hline $50-63$ & $\begin{array}{l}\text { Matérias têxteis } \\
\text { e suas obras }\end{array}$ & 916 & 17.3 & 3.4 & 18.0 & 20.0 & 2.0 \\
\hline $64-67$ & Calçados, chapéus & 62 & 19.1 & 1.4 & 20.0 & 20.0 & 16.0 \\
\hline $68-70$ & Obras de pedra, cimento & 199 & 11.3 & 4.0 & 10.0 & 20.0 & 0.0 \\
\hline 71-71 & Pedras preciosas, etc. & 58 & 10.2 & 6.0 & 18.0 & 18.0 & 0.0 \\
\hline $72-83$ & $\begin{array}{l}\text { Metais comuns } \\
\text { e suas obras }\end{array}$ & 715 & 12.5 & 4.5 & 12.0 & 20.0 & 0.0 \\
\hline $84-85$ & Máquinas e aparelhos & 1.584 & 12.6 & 5.8 & 14.0 & 20.0 & 0.0 \\
\hline $86-89$ & Material de transporte & 197 & 14.8 & 6.2 & 14.0 & 20.0 & 0.0 \\
\hline $90-92$ & Instrumentos de precisão & 442 & 13.6 & 6.0 & 14.0 & 20.0 & 0.0 \\
\hline $93-93$ & Armas e munição & 18 & 20.0 & 0.0 & 20.0 & 20.0 & 20.0 \\
\hline $94-96$ & Mercadorias diversas & 159 & 18.5 & 1.2 & 18.0 & 20.0 & 14.0 \\
\hline \multirow[t]{2}{*}{$97-99$} & Trabalhos de arte & 7 & 4.0 & 0.0 & 4.0 & 4.0 & 4.0 \\
\hline & Média Simples & & 11.2 & 6.2 & 14.0 & 0.0 & 20.0 \\
\hline
\end{tabular}

Fonte: Cálculos dos autores baseado em dados do Comtrade - UNCTAD. 
Embora a TEC tenha sido negociada para todos os produtos, nem todos convergiram imediatamente para os valores estipulados já em janeiro de 1995, pois foram permitidas várias exceções, que constam abaixo:

I) A primeira exceção englobava bens de capitais e equipamentos de tecnologia da informação e de telecomunicações. ${ }^{11}$ Em relação aos bens de capital, Argentina e Brasil iriam convergir para a TEC de $14 \%$ em $1^{\circ}$ de janeiro de 2001 , enquanto os membros menores do bloco deveriam convergir para a TEC somente em $1^{\circ}$ de janeiro de 2006. No que tange aos equipamentos de telecomunicação e da tecnologia de informação, a TEC de 16\% seria atingida somente em $1^{\circ}$ de janeiro de 2006 para todos os membros. ${ }^{12}$

II) Os produtos do regime automotivo e o açúcar também foram alvo de regimes especiais, ${ }^{13}$ assim como ocorreu no comércio intrabloco, não se enquadrando inicialmente à TEC, o que deveria ocorrer somente em janeiro de 2000 e 2001, respectivamente, com os países tendo total liberdade para determinar suas tarifas individualmente até então.

III) Aqueles produtos que pertenciam a regimes especiais de importação constituíam outra perfuração à TEC, recebendo um tratamento diferenciado em cada membro do bloco. ${ }^{14}$

IV) Cada país do Mercosul poderia manter uma lista de exceção à TEC contendo até 300 produtos (399 no caso do Paraguai), ${ }^{15}$ que poderiam ser maiores ou menores do que a TEC, até janeiro de 2001 (janeiro de 2006 para o Paraguai). ${ }^{16}$

V) Ainda outra perfuração à TEC foi permitida para garantir o suprimento normal e contínuo de produtos em casos de escassez de oferta, que vigoraria até 28 de abril de $1996 .{ }^{17}$

11 Decisão No 07/94.

12 Pereira (1999) apontou o conflito de interesses entre Brasil e Argentina em relação a estes setores, o que levou a atrasos na implementação da TEC. Enquanto a Argentina buscou eliminar as tarifas, o Brasil, como o maior produtor destes produtos no bloco, tentou mantê-las.

13 Decisão No 19/94 (açúcar) e Decisão No 29/94 (setor automotivo).

14 Decisão No 21/98.

15 Resolução No 07/94.

16 No entanto, todos os países incluíram menos produtos nesta lista do que havia sido permitido. A Argentina incluiu 231 produtos no SH a 8-dígitos, enquanto Brasil, Paraguai e Uruguai incluíram 171, 214 e 212, respectivamente.

17 Resolução № 22/95. Logo após, a Resolução № 33/98 estendeu a sua duração até 31 de dezembro de 2000. 
VI) Os produtos do "regime de adequação"18 e aqueles incluídos nas negociações bilaterais com outros membros da Associação LatinoAmericana de Integração ${ }^{19}$ (ALADI) também não convergiram imediatamente à TEC, o que deveria ocorrer somente no final de $1999 \mathrm{e}$ 1995, respectivamente.

As muitas perfurações à TEC causaram um número significativo de tarifas de importação não uniformes entre os membros do Mercosul. Considerando-se somente exceções específicas a TEC (casos 1 a 7 da Tabela 2), o Uruguai manteve fora da TEC aproximadamente 2.900 produtos a 8 dígitos do $\mathrm{SH}$, enquanto o Paraguai (2.555 produtos), Argentina (2.236) e Brasil (2.053) também mantiveram um número bastante elevado de exceções à TEC. ${ }^{20}$ Essa proliferação de exceções à TEC minou duas das vantagens de uma união aduaneira em relação às áreas de livre comércio: a ausência de regras de origem e a segurança de acesso ao mercado do bloco. ${ }^{21}$ Em relação às regras de origem, um dos maiores problemas causados pelas exceções à TEC é a necessidade da criação de regras de origem para estes produtos. Originalmente, somente alguns grupos de produtos estariam sujeitos às regras de origem no comércio intrabloco. Entretanto, devido ao aumento das exceções à TEC, todos os produtos ficaram sujeitos ao controle de origem no comércio intrabloco. No caso da segurança de acesso ao mercado, ela é muito importante no caso do Mercosul, pois as tarifas consolidadas de todos os membros do bloco junto à OMC são superiores as suas tarifas praticadas. ${ }^{22}$ Assim, a TEC, mesmo quando fosse maior do que a tarifa vigente antes da formação do bloco, seria uma garantia de que os países do Mercosul não iriam aumentá-la até o limite acordado junto à OMC. ${ }^{23}$

18 Resolução No $48 / 94$.

19 Resolução № 35/92.

20 Na medida em que todos os países mantinham acordos bilaterais com outros membros da ALADI e assumindo que estas preferências incluíam ao menos alguns produtos ausentes da lista de exceção à TEC, é razoável esperar que o número efetivo de exceções à TEC era ainda superior.

21 Ver Krueger (1997) e Kume e Piani (2005) para uma comparação entre os benefícios gerados pelas uniões aduaneiras e zonas de livre comércio.

22 As tarifas máximas de importação dos países do Mercosul determinada pela Rodada Uruguai são de $35 \%$ para produtos manufaturados e 55\% para produtos agrícolas (Trade Policy Review da OMC, 1996, 1997, 1998a, 1998b).

23 As tarifas praticadas ao final da Rodada Uruguai eram significativamente mais baixas do que as tarifas acordadas junto à $\mathrm{OMC}$, devido à liberalização comercial unilateral empreendida pelos membros do Mercosul, entre o final dos anos de 1980 e o início da década de 1990, como demonstrado na seção 2 . 
Tabela 2 - Produtos Excluídos da TEC

\begin{tabular}{|c|c|c|c|c|}
\hline Exceções à TEC & No de Produtos & Prazo / Países & Situação * & Medida \\
\hline 1. Bens de Capital & 1.140 & $\begin{array}{l}\text { 31.12.00/ Arg e Bra } \\
\text { 31.12.05/ Par e Uru }\end{array}$ & Não Atingido & Dec.07/94 \\
\hline $\begin{array}{l}\text { 2. Equip. de tecnologia } \\
\text { da informação e de } \\
\text { telecomunicações }\end{array}$ & 435 & 31.12.05/ Todos & Não Atingido & Dec.07/94 \\
\hline 3. Açúcar & 04 & 31.12.00 / Todos & Não Atingido & Dec.19/94 \\
\hline 4. Setor Automotivo & 95 & 31.12.99/ Todos & Não Atingido & Dec.29/94 \\
\hline 5. Lista de exceção & $\begin{array}{l}300 \\
399\end{array}$ & $\begin{array}{c}\text { 31.12.00/Bra, } \\
\text { Arg e Uru } \\
\text { 31.12.05 / Paraguai }\end{array}$ & Não Atingido & Res.07/94 \\
\hline $\begin{array}{l}\text { 6. Presença no } \\
\text { regime de adequação }\end{array}$ & $\begin{array}{c}\text { Argentina (212) } \\
\text { Brasil (29) } \\
\text { Paraguai (432) } \\
\text { Uruguai (958) }\end{array}$ & $\begin{array}{l}\text { 31.12.98 / Arg e Bra } \\
\text { 31.12.99/ Par e Uru }\end{array}$ & $\begin{array}{l}\text { Atingido } \\
\text { Atingido }\end{array}$ & Res.48/94 \\
\hline 7. Escassez de oferta & 50 & 31.12.00 / Todos & Não Atingido & Res.22/95 \\
\hline $\begin{array}{l}\text { 8. Regimes especiais } \\
\text { de importação }\end{array}$ & Variável & 31.12.00 / Todos & Não Atingido & Dec.21/98 \\
\hline $\begin{array}{l}\text { 9. Acordos bilaterais } \\
\text { de comércio }\end{array}$ & Variável & 31.12.94 / Todos & Não Atingido & Res.35/92 \\
\hline $\begin{array}{l}\text { 10. Aumento de } 3 \\
\text { pontos percentuais }\end{array}$ & $\begin{array}{l}\text { Todos produtos } \\
\text { sujeitos a TEC }\end{array}$ & 31.12.00 / Todos & $\begin{array}{c}\text { Atingido } \\
\text { Tardiamente }\end{array}$ & Dec.15/97 \\
\hline
\end{tabular}

* - situação em dezembro de 2006.

Fonte: Compilação dos autores baseada nas normas do Mercosul.

Entretanto, a administração da TEC foi bastante diferente daquilo que havia sido originalmente estabelecido pelas normas do bloco. Mesmo a existência de muitas exceções não foi suficiente para evitar que novas mudanças na TEC ocorressem após o final do período de transição. Três alterações, decorrentes de instabilidades macroeconômicas causada por crises externas (México - 1994, Sudeste Asiático 1997) ou problemas domésticos (moratória argentina - 2001), merecem destaque. Primeiro, em março de 1995, o bloco concedeu ao Brasil o direito de alterar a TEC de até 150 produtos por um ano para garantir o sucesso de seu recém-lançado plano de estabilização, ameaçado pela crise mexicana. ${ }^{24}$ Para evitar distorções comerciais, os demais membros do bloco também tiveram a permissão de adotar as mesmas alíquotas brasileiras. ${ }^{25}$ Segundo, em novembro de 1997, em decorrência da crise

24 Decisão No 07/95.

25 Assim, tanto Brasil como Argentina elevaram suas tarifas de importação de uma variada gama de produtos, com o primeiro elevando as tarifas de bens de consumo, tais como 
asiática, as regras da TEC foram novamente modificadas. ${ }^{26}$ Todos os membros do Mercosul concordaram em elevar temporariamente a TEC em 3 pontos percentuais entre $1^{\circ}$ de janeiro de 1998 e 31 de dezembro de 2000..$^{27}$ Terceiro, em abril de 2001, a Argentina teve a permissão do bloco para remover alguns bens de consumo e de capital da TEC até 31 de dezembro de 2002, elevando as tarifas dos primeiros até $35 \%$ e reduzindo para zero as tarifas dos últimos. ${ }^{28}$ Dessa forma, o papel esperado da TEC de garantir o acesso ao mercado do bloco com tarifas inferiores às previstas junto à $\mathrm{OMC}$ ficou comprometido.

O impacto das exceções iniciais à TEC e destas medidas pontuais se refletiu na tarifa média de cada país do bloco. Considerando-se a tarifa média de importação do SH a 6 dígitos, é possível identificar precisamente quatro diferentes períodos durante os anos de 1990 (Tabela 3). Durante o período de transição, enquanto a maioria dos países ainda estava envolvida com a redução unilateral das tarifas, a tarifa média declinou substancialmente em todos os membros do Mercosul, especialmente no Brasil. ${ }^{29}$ Contudo, em 1995, quando a TEC foi introduzida e as exceções à TEC foram permitidas, a tarifa média reverteu à tendência anterior e subiu em relação a 1994. De 1995 a 1997, a tarifa média permaneceu estável, pois nenhuma mudança drástica na TEC foi observada. Por fim, a tarifa média voltou a crescer em 1998, devido ao aumento de 3 pontos percentuais na TEC. Portanto, em todos os membros do bloco a tarifa média de importação era maior em 1998 do que em 1994, ano anterior à introdução da TEC. No caso da Argentina, a tarifa média em 1998 era inclusive superior à de 1992, início da formação do bloco.

Além disso, a maioria dos produtos mostrou uma elevação de suas tarifas após 1994. A Tabela 4 compara o percentual dos produtos que tiveram suas tarifas elevadas em cada membro do Mercosul em quatro momentos críticos da formação do bloco: (I) o primeiro ano do período de transição (1991); (II) o último ano do período de transição (1994); (III) o primeiro ano da união aduaneira incompleta (1995); e (IV) o ano imediatamente após o aumento de 3 pontos percentuais da TEC (1998). Durante o período de transição, a maioria dos produtos em todos os membros do

automóveis, brinquedos e calçados para o limite de 35\% tolerado pela OMC, enquanto a Argentina alterou as tarifas de bens de capital e de telecomunicações.

26 Vale notar que a Argentina já havia elevado sua tarifa de importação, em 1995, em 3 pontos percentuais com a denominação de taxa de estatística.

27 Decisão № $15 / 97$. O Uruguai e Paraguai, no entanto, foram contrários à ampla abrangência desta medida e a aplicaram seletivamente.

28 Decisão № 01/01.

29 Os dados sobre tarifas para o Uruguai em 1994 não estavam disponíveis na base de dados da UNCTAD, mas os relatórios de política comercial da OMC sugerem que elas seguiram o mesmo padrão dos demais países do Mercosul. 
bloco teve suas tarifas reduzidas. No caso do Brasil, só 0,6\% dos produtos mostraram uma elevação de tarifas, enquanto $83,8 \%$ declinaram nesse período. Isso se deveu ao processo de redução unilateral das tarifas de importação ocorrido neste período. Já na comparação entre 1994 e 1995, o número de produtos que teve as suas tarifas elevadas em 1995 em relação ao ano anterior foi muito superior ao que sofreu reduções tarifárias, em todos os membros do bloco, atingindo um pico na Argentina, onde $64,5 \%$ dos produtos tiveram incremento de tarifas. De 1994 a 1998, em todos os membros o número de produtos com elevação de tarifas excedeu $60 \%$. A Argentina simboliza o que ocorreu neste período, pois para cada produto com redução de tarifa outros 11 mostraram elevação. Em relação ao período 1991-1998, na Argentina, onde a redução unilateral das tarifas estava no processo final em 1992, a maioria das tarifas subiu, enquanto no Brasil e Paraguai, onde a abertura comercial unilateral coincidiu com o período de transição, a tarifa da maioria dos produtos declinou.

Tabela 3 - Tarifa de Importação a 6 dígitos do SH por membros do Mercosul, 1991-98 (\%)

\begin{tabular}{c|c|r|r|r|r|r|r}
\hline País & Medidas & \multicolumn{1}{|c|}{$1991^{*}$} & 1994 & 1995 & 1996 & 1997 & 1998 \\
\hline \multirow{4}{*}{ Argentina } & Média Simples & 12.63 & 9.87 & 12.10 & 12.76 & 12.86 & 15.28 \\
& Picos & 35.00 & 20.00 & 29.00 & 30.00 & 30.00 & 33.00 \\
& Vales & 0.00 & 0.00 & 0.00 & 0.00 & 0.00 & 0.00 \\
\hline \multirow{3}{*}{ Brasil } & Média Simples & 26.10 & 12.82 & 13.05 & 13.39 & 13.11 & 15.94 \\
& Picos & 85.00 & 40.00 & 32.00 & 70.00 & 63.00 & 49.00 \\
& Vales & 0.00 & 0.00 & 0.00 & 0.00 & 0.00 & 0.00 \\
\hline \multirow{3}{*}{ Paraguai } & Média Simples & 15.53 & 7.90 & 10.74 & 10.98 & 11.08 & 11.14 \\
& Picos & 72.00 & 32.00 & 20.00 & 30.00 & 25.00 & 30.00 \\
& Vales & 0.00 & 0.00 & 0.00 & 0.00 & 0.00 & 0.00 \\
\hline \multirow{4}{*}{ Uruguai } & Média Simples & 16.58 & n.d. & 10.91 & 11.31 & 11.43 & 13.70 \\
& Picos & 24.00 & n.d. & 32.00 & 30.00 & 27.00 & 24.00 \\
& Vales & 10.00 & n.d. & 0.00 & 0.00 & 0.00 & 0.00 \\
\hline
\end{tabular}

* 1992 para Argentina e Uruguai.

n.d. - não disponível.

Fonte: Cálculos dos autores, baseados na base de dados da UNCTAD.

Esses resultados, baseados tanto na tarifa média como na variação das tarifas dos produtos ao nível do $\mathrm{SH}$ a 6 dígitos, sugerem que a queda das tarifas entre 1991 e 1994 ocorreu apesar do Mercosul, pois cada país do bloco ainda tinha autonomia de suas tarifas e estava envolvido em um processo de liberalização comercial unilateral, conforme explicado na seção 2. Entretanto, a elevação observada a partir de 1995 parece estar relacionada à formação do bloco, devido à introdução da TEC e suas inúmeras exceções. Assim, a partir do final do período de transição, houve um 
aumento do grau de discriminação contra os países de fora do bloco. Mas o que poderia ter influenciado este comportamento da TEC no Mercosul?

A literatura aponta duas abordagens para explicar a determinação da TEC em uma união aduaneira. A primeira vincula o estabelecimento da TEC à tentativa de internalização por parte dos membros do bloco de ganhos ligados a uma melhoria dos seus termos de troca (abordagem dos termos de troca). Se os países tendem a importar os mesmos produtos, ao formar uma união aduaneira eles estariam aumentando seu poder de mercado. Assim, de acordo com esta abordagem, a TEC deveria provocar uma elevação das tarifas de importação para os não-membros após a formação do bloco (BOND; SYROPOULOS, 1996). Essa abordagem pode parecer pouco factível para explicar a configuração da TEC do Mercosul, dado a pequena relevância destes países no comércio mundial. No entanto, os maiores países do Mercosul, Argentina e Brasil, são suficientemente grandes para influenciar os preços de determinados produtos no mercado internacional. De acordo com Chang e Winters (1999), a formação do Mercosul gerou uma melhoria dos termos de troca para uma série de produtos. ${ }^{30}$ Além disso, os efeitos sobre os termos de troca podem causar externalidades sobre os preços dos países que comercializam bens similares. Assim, quando o Brasil eleva as suas tarifas de importação, isso causa uma externalidade positiva para a Argentina, pois as suas importações também ficam mais baratas. Conforme Olarreaga et al. (1999), como a Argentina tende a importar bens similares aos que o Brasil importa, a internalização da externalidade positiva sobre os termos de troca deve levar a um efeito ainda maior dos termos de troca na composição da TEC, contribuindo para sua elevação. ${ }^{31}$

A segunda abordagem, conhecida como formação endógena de tarifas, busca explicar a formatação da TEC como uma forma de redistribuir renda para determinados grupos organizados da sociedade. ${ }^{32}$ Essa abordagem, por sua vez, apresenta resultados dúbios no que se refere à evolução do grau de protecionismo em relação aos países não-membros do bloco. De um lado, alguns autores argumentam que as tarifas deveriam declinar após a formação do bloco, pois na medida em que o tamanho do grupo de lobistas aumentasse ficaria mais difícil a sua organização e, portanto, a efetividade do lobby perderia força (RICHARDSON, 1994). ${ }^{33}$ Entretanto, outros afirmam que as tarifas poderiam aumentar devido a não-linearidades na determinação da TEC. Nesse caso, a negociação

30 Os ganhos estão associados principalmente à queda de preço das importações.

31 Os autores identificaram uma relação positiva entre as importações da Argentina e do Brasil, baseados na classificação ISIC, a 4 dígitos.

32 Ver Winters (1996) para maiores detalhes sobre estas duas abordagens.

33 Isto ocorreria devido ao problema de free-riding em grupos grandes. 
da TEC de um produto qualquer em uma união aduaneira geralmente refletiria os interesses dos grupos de pressão localizados nos países com um maior nível de produção deste produto. Assim, um país com uma elevada produção de um determinado setor iria exercer uma pressão para mantê-lo protegido nas negociações da TEC (CADOT et al., 1996). No caso do bloco, os grupos de interesse nacionais parecem não ter perdido influência a nível regional (OLARREAGA; SOLOAGA, 1998; OLARREAGA et al., 1999), configurando, assim, mais um motivo para a elevação da TEC em relação à situação anterior a formação do bloco. Bhagwati (1993) descreve este fenômeno como a síndrome "este mercado é nosso", que estabelece que, em um ambiente onde os produtores detêm um papel importante na determinação das políticas comerciais, a formação do bloco pode levar a um aumento do protecionismo em relação aos países de fora do bloco. Portanto, parece haver um suporte teórico bastante robusto para justificar a evidência empírica que apontou a elevação do grau de protecionismo do Mercosul em relação a países não membros do bloco após a implementação da TEC, conforme descrito neste artigo.

Tabela 4 - Mudança das tarifas de importação a 6 dígitos do SH por membros do Mercosul, 1991-98 (\%)

\begin{tabular}{c|c|c|c|c}
\hline Períodos & Argentina * & Brasil & Paraguai & Uruguai $^{* * *}$ \\
\hline $1991<1994$ & 22.0 & 0.8 & 6.9 & - \\
$1991>1994$ & 64.9 & 83.8 & 86.6 & - \\
\hline $1994<1995$ & 64.5 & 34.7 & 62.1 & - \\
$1994>1995$ & 18.3 & 24.7 & 27.5 & - \\
\hline $1994<1998$ & 88.3 & 78.9 & 62.6 & 92.7 \\
$1994>1998$ & 7.9 & 11.6 & 26.1 & 3.6 \\
\hline $1991<1998$ & 64.1 & 19.0 & 33.0 & 83.0 \\
$1991>1998$ & 27.5 & 78.5 & 60.4 & 15.0 \\
\hline
\end{tabular}

* - 1992 ao invés de 1991 para a Argentina.

** - 1992 ao invés de 1991 e 1995 ao invés de 1994 para Uruguai.

Fonte: Cálculos dos autores, baseados em dados da UNCTAD.

\section{Considerações Finais}

O processo de integração perseguido pelos membros do Mercosul desde 1991 obteve avanços reais, tais como a remoção das tarifas e barreiras não-tarifárias intrabloco e o estabelecimento de uma tarifa externa comum para muitos produtos. Entretanto, uma série de acontecimentos externos, como a instabilidade macroeconômica causada por crises externas ou problemas domésticos, bem como os interesses 
de grupos de pressão têm sistematicamente desviado o bloco de atingir muitos de seus ambiciosos objetivos nos prazos previstos. Os eventos desde a introdução da TEC, em 1995, têm mostrado que a estratégia de liberalização externa esteve bastante suscetível aos interesses dos grupos de pressão domésticos. Assim, sempre que houve um conflito entre o interesse nacional e as regras do bloco, os membros do Mercosul invariavelmente optaram por mudar as regras do jogo ou adicionar mais furos ou brechas ao acordo.

Ainda durante a fase de transição do Mercosul (1991-94), quando os países ainda detinham o controle de suas tarifas extrabloco, os países que originalmente formaram o Mercosul seguiram a mesma tendência dos demais países da América Latina, reduzindo unilateralmente as suas estruturas protecionistas. Ao longo desse período, a média e a dispersão das tarifas de importação declinaram significativamente. Assim, antes da introdução da TEC, os países apresentavam tarifas de importação muito mais baixas do que aquelas praticadas na década anterior.

No entanto, a forma através da qual a TEC foi determinada e administrada - caracterizada pela elevação da maior parte das tarifas em relação à situação anterior à formação da união aduaneira, pelo grande número de exceções à TEC inicialmente permitido, pela proliferação de novas exceções após o período de transição e pelos atrasos na eliminação das exceções originais - contribuiu para a reversão da tendência de liberalização comercial iniciada ainda nos anos de 1980 pelos membros do bloco. Esses fatos sugerem que a abordagem dos termos de troca, bem como da formação endógena de tarifas, que foram capazes de influenciar a determinação da TEC, elevando-a em relação ao período anterior a formação do bloco, mantiveram a sua influência no período posterior. Para que o processo de integração avance e efetivamente se transforme em uma união aduaneira, parece necessária, além de certa estabilidade macroeconômica na região, uma maior disposição dos governos nacionais em privilegiar o desenvolvimento do bloco, mesmo que isso represente um custo político elevado.

\section{Referências}

AZEVEDO, A. Mercosur: ambitious policies, poor practices. Revista de Economia Política, v. 24, p. 584-601, 2004.

AZEVEDO, A.; PORTUGAL, M. Abertura Comercial Brasileira e Instabilidade da Demanda de Importações. Nova Economia, Belo Horizonte, 8, p. 37-63, 1998.

BERLINSKI, J. Post-trade liberalisation issues in Argentina. Series Documentos de Trabajo, 182. Buenos Aires: Instituto Torcuato di Tella, 1994. 
BHAGWATI, J. Regionalism and multilateralism: An overview. In: DE MELO, J.; PANAGARIYA; A. (Eds.). New Dimensions in Regional Integration. New York: Cambridge University Press, 1993. p. 22-51.

BID - Banco Inter-Americano de Desenvolvimento. Mercosur Report, Buenos Aires, $\mathrm{n}^{\circ}$ 1, 1996. Disponível em: <http://www.iadb.org/intal/.> Acesso em: out. 2006.

. Mercosur Report, Buenos Aires, n 11, 2006. Disponível em: < http://www.iadb. org/intal/.> Acesso em: out. 2006.

BOND, E; SYROPOULOS, C. The size of trading blocs market power and world welfare effects. Journal of International Economics, 40, p. 411-437, 1996.

CADOT, O.; MELO, J.; OLARREAGA, M. Regional integration and lobbying for tariffs against non-members. CEPR Discussion Paper n. 1448. London: CEPR, 1996.

CHANG, W.; WINTERS; A. The price effects of regional integration: non-member reaction to Mercosur. World Bank Policy Research Working Paper n 2157, 1999.

EDWARDS, S. Trade liberalisation reforms in Latin America: Recent experiences, policy issues and future prospects. In: Bird, G.; Helwege, A. (Eds.). Latin America's Economic Future. London: Academic Press, 1994. p.11-50.

EDWARDS, S. Crisis and Reforms: Form Despair to Hope. New York: Oxford University Press, 1995.

ESTEVADEORDAL, A.; GOTO, J.; SAEZ; R. The new regionalism in the Americas: The case of Mercosur. Intal Discussion Paper, 05. Buenos Aires: 2000. Disponível em <http:// www.iadb.org/intal/publicaciones/estevadeordal-goto-saez.pdf. > Acesso em: nov. 2005.

ETHIER, W. The new regionalism. The Economic Journal, 449, p. 1149-1161, 1998.

GROSSMAN, G; HELPMAN, E. The politics of free trade agreements. American Economic Review, 85, p. 667-690, 1995.

HOEKMAN, B.; LEIDY, M. Holes and loopholes in the integration agreements: History and prospects. In: Anderson, K.; Blackhurst, R. (Eds.). Regional Integration and the Global Trading System. London: Harvester-Wheatsheaf, 1993. p. 218-245.

KRUEGER, A. Free trade agreements versus customs unions. Journal of Development Economics, 54, p. 169-187, 1997.

KUME, H. A política de importação no Plano Real e a estrutura de proteção efetiva. A Economia Brasileira em Perspectiva - 1998. Rio de Janeiro: IPEA, 1998.

KUME, H.; PIANI, G. Mercosul: O dilema entre união aduaneira e área de livre comércio. Revista de Economia Política, 25, p. 370-390, 2005.

LAIRD, S. Mercosur: objectives and achievements. WTO Staff Working Paper, TPRD-97002. Geneva: World Trade Organization, 1997.

LAWRENCE, R. Preferential trading arrangements: The traditional and the new. In: Galal, A.; Hoekman, B. (Eds.). Regional Partners in Global Markets. CEPR, Egypt: The Egyptian Center for Economic Studies, World Trade Center, 1997. p. 13-34.

LOAYZA, N.; PALACIOS, L. Economic reform and progress in Latin America. Policy Research Working Paper, no 1829. World Bank, 1997. Disponível em: <http://econ. worldbank.org/docs/533.pdf. > Acesso em: set. 2005. 
LOSER, C.; GUERGUIL, M. Trade and trade reform in Latin America and the Caribbean in the 1990s. Journal of Applied Economics, 01, p. 61-96, 1999. Disponivel em: < http://www. cema.edu.ar/publicaciones/download/volume2/loser_guerguil.pdf.> Acesso em: set. 2005.

OLARREAGA, M.; SOLOAGA, I. Endogenous tariff formation: The case of Mercosur. World Bank Economic Review, 12, p. 297-320, 1998.

OLARREAGA, M.; SOLOAGA, I.; WINTERS, A. What's Behind Mercosur's Common External Tariff? Policy Research Working Paper, n. 2231. Washington DC: World Bank, 1999.

OMC - Organização Mundial de Comércio. Trade Policy Review: Brazil. Genebra: OMC, 1996. Disponível em: < http://www.wto.org/english/tratop_e/tpr_e/tp45_e.htm.> Acesso em: out. 2006.

. Trade Policy Review: Paraguay. Genebra: OMC, 1997. Disponível em: <http:// www.wto.org/english/tratop_e/tpr_e/tp57_e.htm.> Acesso em: out. 2006.

. Trade Policy Review: Uruguay. Genebra: OMC, 1998a. Disponível em: < http:// www.wto.org/english/tratop_e/tpr_e/tp91_e.htm.> Acesso em: out. 2006.

. Trade Policy Review: Argentina. Genebra: OMC, 1998b. Disponível em: < http:// www.wto.org/english/tratop_e/tpr_e/tp100_e.htm.> Acesso em: out. 2006.

PEREIRA, L. Toward the common market of the South: Mercosur's origins, evolution, and challenges. In: Roett, R (Ed.). Mercosur: Regional Integration, World Markets. London: Lynne Rienner, 1999. p. 7-23.

PREUSSE, H. Mercosur - Another failed move towards regional integration? World Economy, 24, p. 911-931, 2001.

RICHARDSON, M. Why a free-trade area? The tariffs also rises. Economics and Politics, 6, p. 79-96, 1994.

VEIGA, P. Brazil in Mercosur: Reciprocal influence. In: Roett, R. (Ed.). Mercosur: Regional Integration, World Markets. London: Lynne Rienner, 1999. p. 25-33.

VINER, J. The Custom Union Issue. London: Carnegie Endowment for International Peace, 1950.

WINTERS, A. Regionalism versus Multilateralism. CEPR Discussion Paper n. 1525. London: CEPR, 1996.

Recebido em: 10/04/2008. Aceito em: 23/09/2008. 